\title{
Matrix Metalloproteinase-9 Gene Knock-out Protects the Immature Brain after Cerebral Hypoxia-Ischemia
}

\author{
Pernilla Svedin, ${ }^{1}$ Henrik Hagberg, ${ }^{2}$ Karin Sävman, ${ }^{2}$ Changlian Zhu,${ }^{3,4}$ and Carina Mallard ${ }^{1}$ \\ Departments of ${ }^{1}$ Neuroscience and Physiology and ${ }^{2}$ Clinical Sciences, Perinatal Center, Sahlgrenska Academy, and ${ }^{3}$ Center for Brain Repair and \\ Rehabilitation, Institute of Neuroscience and Physiology, Göteborg University, 40530 Göteborg, Sweden, and ${ }^{4}$ Department of Pediatrics, The Third \\ Affiliated Hospital of Zhengzhou University, Zhengzhou 450052, China
}

Inhibition of matrix metalloproteinase-9 (MMP-9) protects the adult brain after cerebral ischemia. However, the role of MMP-9 in the immature brain after hypoxia-ischemia (HI) is unknown. We exposed MMP- $9^{(-/-)}$[MMP-9 knock-out (KO)] and wild-type (WT) mice to $\mathrm{HI}$ on postnatal day 9 . $\mathrm{HI}$ was induced by unilateral ligation of the left carotid artery followed by hypoxia $\left(10 \% \mathrm{O}_{2} ; 36^{\circ} \mathrm{C}\right)$. Gelatin zymography showed that MMP-9 activity was transiently increased at $24 \mathrm{~h}$ after $\mathrm{HI}$ in the ipsilateral hemisphere and MMP-9-positive cells were colocalized with activated microglia. Seven days after $50 \mathrm{~min}$ of HI, cerebral tissue volume loss was reduced in MMP-9 KO (21.8 \pm $\left.1.7 \mathrm{~mm}^{3} ; n=22\right)$ compared with WT $\left(32.3 \pm 2.1 \mathrm{~mm}^{3} ; n=22 ; p<0.001\right)$ pups, and loss of white-matter components was reduced in MMP-9 KO compared with WT pups (neurofilament: WT, $50.9 \pm 5.4 \%$; KO, $18.4 \pm 3.1 \% ; p<0.0001$; myelin basic protein: WT, $57.5 \pm$ $5.8 \%$; KO, $23.2 \pm 3.5 \% ; p=0.0001$ ). The neuropathological changes were associated with a delayed and diminished leakage of the blood- brain barrier (BBB) and a decrease in inflammation in MMP-9-deficient animals. In contrast, the neuroprotective effects after HI in MMP-9-deficient animals were not linked to either caspase-dependent (caspase-3 and cytochrome $c$ ) or caspase-independent (apoptosis-inducing factor) processes. This study demonstrates that excessive activation of MMP-9 is deleterious to the immature brain, which is associated with the degree of BBB leakage and inflammation. In contrast, apoptosis does not appear to be a major contributing factor.

Key words: neonatal; inflammation; cerebral palsy; apoptosis; caspase; extracellular matrix

\section{Introduction}

Matrix metalloproteinase-9 (MMP-9; gelatinase B) belongs to a subgroup of gelatinases in the family of zinc-dependent extracellular peptidases, so-called matrix metalloproteinases, that are able to modify components of the extracellular matrix (Yong et al., 1998). MMP-9 is important for normal brain development but can be harmful when activated under pathological conditions (Van den Steen et al., 2002).

MMP-9 has been shown to degrade collagen type IV in the basement membranes of endothelial walls, which may lead to disruption of the blood-brain barrier (BBB) after both cerebral ischemia and inflammation, allowing entry of leukocytes or cytokines into the brain (Rosenberg et al., 1994; Mun-Bryce and Rosenberg, 1998; Sellebjerg and Sorensen, 2003). Excessive extracellular proteolytic activity of MMP-9 after cerebral ischemia in adult mice has also been shown to degrade white-matter components, including myelin basic protein (MBP) (Asahi et al., 2001).

\footnotetext{
Received 0ct. 9, 2006; revised Dec. 18, 2006; accepted Jan. 2, 2007.

This work was supported by Swedish government grants to researchers in public service (ALFGBG-2863), the Swedish Research Council (K2004-33X-14185-03A and VR2003-4155), the Laerdal Foundation, the Åhlen Foundation, the Sven Jerring Foundation, the Wilhelm and Martina Lundgren Foundation, and the Frimurare Barnhus Foundation, Göteborg Medical Society. We thank Josefin Caous for her excellent technical assistance.

Correspondence should be addressed to Dr. Carina Mallard, Perinatal Center, Department of Neuroscience and Physiology, Sahlgrenska Academy, Göteborg University, P.0. Box 432, 40530 Göteborg, Sweden. E-mail: carina.mallard@gu.se.

D0I:10.1523/JNEUROSCI.4391-06.2007

Copyright $\odot 2007$ Society for Neuroscience $\quad$ 0270-6474/07/271511-08\$15.00/0
}

Studies in adult animals have demonstrated a role for MMP-9 in ischemic brain injury, because inhibition of MMP-9 activation, either by knockout of the gene or by administration of an inhibitor, is associated with reduced brain injury and attenuation of BBB leakage (Romanic et al., 1998; Asahi et al., 2000).

There is also evidence to suggest that MMPs are involved in regulation of intracellular proteolytic cascades. MMPs, including MMP-9, may regulate inflammatory processes, because it has been shown to process proinflammatory cytokines such as interleukin- $1 \beta$ (IL-1 $\beta)$ into its biologically active and mature form (Schonbeck et al., 1998). Furthermore, recent studies have suggested that MMPs play a role in cell death via apoptotic mechanisms, including caspase-dependent cascades (Mannello et al., 2005).

The pathogenesis of brain injury is age dependent and particularly inflammatory, and caspase-dependent processes appear to be important in the immature brain (Vannucci and Hagberg, 2004). However, the role of MMP-9 in the developing brain after injury has not been evaluated. The purpose of this study was therefore to examine the role of MMP-9 in neonatal brain injury, in a well established model of hypoxia-ischemia (HI). Using 9-dold MMP-9 knock-out (KO) mice, we examined tissue loss, damage to the white matter and BBB, and the effects on apoptosis and inflammation after HI.

\section{Materials and Methods}

Induction of HI in postnatal day 9 mice

MMP- $9^{(-1-)}$ and wild-type (WT) animals were bred from C57BL/6 heterozygote mice (Vu et al., 1998) at Experimental Biomedicine (Sahlgren- 
ska Academy, Göteborg University), with ad libitum access to food and water. The animal experiments were approved by the local Ethical Committee of Göteborg University.

HI was induced on postnatal day 9 (P9) as described previously (Rice et al., 1981; Hedtjarn et al., 2002), with some modifications. The pups were anesthetized with isoflurane (Forene; 3.5\% for induction, $1.5 \%$ for maintenance) in a mixture of nitrous oxide and oxygen (1:1), and the left common carotid artery was permanently ligated (prolene 6.0). The incision was closed (prolene 5.0) and infiltrated with local anesthetic after the procedure. The duration of anesthesia was $<5 \mathrm{~min}$. After a recovery period with the dam $(1 \mathrm{~h})$, the pups were exposed to a humidified gas mixture ( $10 \%$ oxygen in nitrogen) for 50 or $60 \mathrm{~min}$ at $36^{\circ} \mathrm{C}$. The temperature in the incubator and the temperature of the water used to humidify the gas mixture were kept at $36^{\circ} \mathrm{C}$. After hypoxic exposure, the pups were returned to their dam.

\section{Genotyping: DNA preparation and PCR}

The genotype of the mice was determined by PCR analysis of DNA that was extracted from the tail. Approximately $2 \mathrm{~mm}$ of tissue was digested in buffer (50 mm Tris-HCl, pH 8.0, $100 \mathrm{~mm}$ EDTA, $100 \mathrm{~mm} \mathrm{NaCl}$, and 1\% SDS) containing $1 \mathrm{mg} / \mathrm{ml}$ proteinase-K (Roche Diagnostics, Penzberg, Germany) overnight at $60^{\circ} \mathrm{C}$. To extract the DNA, one-half the original volume of potassium acetate, $5 \mathrm{M}$, was added, and the mixture was centrifuged at 13,000 rpm for $20 \mathrm{~min}$. The supernatant was saved and mixed with double the original volume of $100 \%$ ethanol and incubated at $-20^{\circ} \mathrm{C}$ for at least $30 \mathrm{~min}$. To precipitate the DNA, the mixture was centrifuged at $13,000 \mathrm{rpm}$ for $25 \mathrm{~min}$ at $4^{\circ} \mathrm{C}$. Pellets were washed with $75 \%$ ethanol and left to dry after removal of the liquid. The DNA was dissolved in $50 \mu \mathrm{l}$ of sterile $\mathrm{H}_{2} \mathrm{O}$.

Two microliters of the extracted DNA were added to the reaction mixture [ $1 \times$ PCR buffer $(250 \mathrm{~mm}$ Tris- $\mathrm{HCl}, \mathrm{pH} 8.3,375 \mathrm{~mm} \mathrm{KCl}, 15 \mathrm{~mm}$ $\mathrm{MgCl}_{2}$; Sigma-Aldrich, St. Louis, MO), $200 \mu \mathrm{M} \mathrm{dNTP,} 0.5 \mu \mathrm{M}$ Primer 1-4, and $0.04 \mathrm{U} / \mu \mathrm{l} \mathrm{Taq}$ polymerase (Sigma-Aldrich)], which had a total volume of $25 \mu \mathrm{l}$. The primers (Cybergene, Huddinge, Sweden) that were used showed the WT ( $5^{\prime}$-ATG ATT GAA CAA GAT GGA TTG CAC G-3', 5' -TTC GTC CAG ATC ATC CTG ATC GAC-3') band of $300 \mathrm{bp}$, the MMP-9-deficient (5'-GCA TAC TTG TAC CGC TAT GG-3', 5'TAA CCG GAG GTG CAA ACT GG-3') band of $480 \mathrm{bp}$, or the heterozygote mice that showed both bands (see Fig. $1 A$ ). The reaction consisted of 32 cycles: denaturation, $94^{\circ} \mathrm{C}, 45 \mathrm{~s}$; annealing, $60^{\circ} \mathrm{C}, 45 \mathrm{~s}$; elongation, $72^{\circ} \mathrm{C}, 1 \mathrm{~min} 30 \mathrm{~s}$. The PCR products were analyzed by using Tris-borateEDTA buffer agarose electrophoresis (1.5\%) labeled with ethidium bromide. The bands were visualized by using a LAS- 100 cooled CCD camera (Fujifilm, Tokyo, Japan).

\section{Gelatin zymography}

To confirm the activation of MMP-9, gelatin zymography was performed at $1,3,6,24$, and $72 \mathrm{~h}$ after $60 \mathrm{~min}$ HI. Pups ( $n=3$ per time point) were killed with an overdose of thiopental (pentothal sodium, intraperitoneally) and perfused with cold saline, and the brains were rapidly removed and divided into an ipsilateral ischemic hemisphere and a contralateral nonischemic hemisphere. Control animals, 9 and $12 \mathrm{~d}$ old $(n=3$ per time point), were treated in the same way as the $\mathrm{HI}$ animals. Hemispheric tissue was frozen immediately in isopentane and stored at $-80^{\circ} \mathrm{C}$.

The frozen brain samples were homogenized and solubilized in $0.5 \%$ Triton X-100 in PBS, pH 7.0, for $24 \mathrm{~h}$ at $4^{\circ} \mathrm{C}$. The homogenate was centrifuged at 13,000 rpm for $10 \mathrm{~min}$ at $4^{\circ} \mathrm{C}$. Total protein concentration in the supernatants was measured by Soft Max PRO 3.0.

The samples were mixed with one-part $2 \times$ Tris-glycine SDS sample buffer [12.5 mм Tris-0.5 м HCl, pH 6.8, 20\% glycerol, 4\% SDS (w/v), and $0.005 \%$ bromophenol blue $(\mathrm{w} / \mathrm{v})]$, and the mixtures were left at room temperature for $10 \mathrm{~min}$. The samples $(20 \mu \mathrm{l} /$ well $)$ were applied on a $10 \%$ polyacrylamide gel containing $0.1 \%$ gelatin, and the gel was electrophoresed with $1 \times$ Tris-glycine SDS electrode buffer $(25 \mathrm{~mm}$ TrizmaBase, $190 \mathrm{~mm}$ glycin, and $3.5 \mathrm{~mm}$ SDS) according to standard running conditions. After running, the gel was first incubated with zymogram renaturing buffer $[2.5 \%$ Triton X-100 (v/v)] with gentle agitation for 30 $\mathrm{min}$ at room temperature. Then the gel was incubated in fresh zymogram renaturing buffer overnight at $37^{\circ} \mathrm{C}$ for maximum sensitivity. Coomassie blue R-250 (0.5\%; w/v) in fixative [methanol/acetic acid/water (50:10: $40)$ ] was used for visualizing the areas of protease activity, followed by destaining [methanol/acetic acid/water (50:10:40)]. Human MMP-9 and MMP-2 (Millipore, Bedford, MA) were used as standards.

\section{Immunohistochemical procedures}

Immunohistochemistry was performed as described previously (Zhu et al., 2000; Svedin et al., 2005). Briefly, sections were deparaffinized, hydrated in xylene and graded alcohol, boiled in citric acid buffer $(0.01 \mathrm{M}$, $\mathrm{pH}$ 6.0), followed by blocking of endogenous peroxidase and nonspecific binding [PBS ( $0.1 \mathrm{M}, \mathrm{pH} 7.2)$ containing $3 \%$ bovine serum albumin and $1 \%$ goat or horse serum as appropriate], and incubated with primary antibodies and appropriate secondary antibodies. To visualize immunoreactivity, sections were incubated with avidin-biotinylated enzyme complex (20 $\mu \mathrm{l} / \mathrm{ml}$, Vectastain ABC Elite kit; Vector Laboratories, Burlingame, $\mathrm{CA}$ ), followed by 3,3-diaminobenzidine (DAB), and enhanced with $15 \mathrm{mg} / \mathrm{ml} \mathrm{NiSO}_{4}$. The sections were dehydrated in graded ethanol and xylene and coverslipped with mounting medium.

The following primary antibodies and dilutions were used: mouse monoclonal anti- microtubule-associated protein-2 (MAP-2; 1:2000, M4403; Sigma-Aldrich); mouse monoclonal anti-MBP (1:10,000, SMI 94; Sternberger Monoclonal, Lutherville, MD); mouse monoclonal antiphosphorylated neurofilaments (NFs; 1:2000, SMI312; Sternberger Monoclonal); goat polyclonal anti-apoptosis inducing factor (AIF; 1:100, sc-9416; Santa Cruz Biotechnology, Santa Cruz, CA); mouse monoclonal anti-cytochrome $c(1: 400,556433)$ and rabbit polyclonal anti-active caspase-3 (1:50, 557035) (both from BD Biosciences PharMingen, San Diego, CA); and polyclonal anti-MMP-9 (1:10,000, ab16306) and polyclonal anti-laminin (1:250, ab11575) (both from Abcam, Cambridge, UK). Nuclear staining was performed with $1 \mu \mathrm{g} / \mathrm{ml} 4^{\prime}$-6-diamidino-2phenylindole (DAPI; Invitrogen, San Diego, CA) in PBS for $5 \mathrm{~min}$ at room temperature with gentle agitation.

Microglia cells were visualized by Griffonia simplicifolia isolectin- $\mathrm{B}_{4}$ $(10 \mu \mathrm{g} / \mathrm{ml})$, which was horseradish peroxidase (L5391; Sigma-Aldrich) and $\mathrm{DAB}$ labeled.

\section{Neuropathological outcome}

Brain injury evaluation. The pups were killed on P16 for evaluation of brain infarction. Animals were anesthetized with thiopental (pentothal sodium) and perfusion fixed with 5\% paraformaldehyde (Histofix; Histolab, Göteborg, Sweden), and the brains were dehydrated and embedded in paraffin. Evenly spaced coronal sections $(5 \mu \mathrm{m})$ throughout the brain were stained with MAP-2, which labels neurons and dendrites. Microscope images were captured by a CCD camera (DP50; Olympus Optical, Tokyo, Japan), and the area of MAP-2-positive staining in each hemisphere was measured (MicroImage, version 4.0; Olympus Optical). The MAP-2-positive area in the ipsilateral hemisphere was subtracted from the contralateral hemisphere for each brain level and expressed as the percentage of tissue loss of the contralateral hemisphere. The total volume of tissue loss was calculated according to the Cavalieri Principle, in which the area of tissue loss at each level was calculated by subtracting the MAP-2-positive area in the ipsilateral area from the contralateral hemisphere. The following formula was used: $V=\Sigma A \times P \times T$, where $V$ is the total volume, $\Sigma A$ is the sum of areas measured, $P$ is the inverse of the sampling fraction of the section, and $T$ is the section thickness.

White-matter damage. The loss of white matter was measured immunohistochemically by the presence of MBP and NF on P16 in sections at the striatum and hippocampal levels, as demonstrated previously (Hedtjarn et al., 2002). Microscope images were captured (10× magnification) by a CCD camera (DP50; Olympus Optical), and the area of the subcortical MBP respective to the NF-positive staining in each hemisphere was measured (MicroImage, version 4.0; Olympus Optical). The ipsilateral hemisphere was compared with the contralateral hemisphere, and the values were expressed as a percentage of tissue loss.

\section{Inflammation}

Microglial cells in the injured hemisphere at the hippocampal level were detected by isolectin histochemistry at $6 \mathrm{~h}, 24 \mathrm{~h}$, and $7 \mathrm{~d}$ after the HI insult. The number of activated microglial cells were estimated (at $20 \times$ magnification) in the cerebral cortex, subcortical white matter, hip- 
pocampus, and thalamus according to the following scale: $0=0$ microglia cells; $1=1-25$ cells; $2=26-50$ cells; $3=51-75$ cells; $4=>75$ cells.

\section{General cell death and apoptotic markers}

Both caspase-dependent and -independent pathways of cell death were investigated by immunohistochemical staining of AIF ( $6 \mathrm{~h}$ after $\mathrm{HI}$ ), cytochrome $c$ (6 h after HI), and caspase-3 (24 h after HI). AIF-, cytochrome $c$-, and caspase-3-positive cells were counted within a predetermined field $\left(0.078 \mathrm{~mm}^{2}\right)$ in the ipsilateral hemisphere at the hippocampal level at $400 \times$ magnification in the cerebral cortex and the hippocampus. Cells in four fields per brain region were counted and expressed as the mean number of cells per square millimeters. General cell death was investigated according to morphological hallmarks of cell death by examining DAPI nuclear staining. The number of cells with DNA damage were counted in the penumbra of the cerebral cortex in four visual fields per animal (each field was $0.324 \mathrm{~mm}^{2}$ ) and expressed as the mean number of cells per square millimeters.

\section{Cellular immunoreactivity of MMP-9}

The immunohistochemical presence of MMP- 9 was determined in different brain regions at $0,1,3,6,24$, and $72 \mathrm{~h}$ after $\mathrm{HI}$ in WT animals. MMP-9 KO mice were used as negative controls. The cellular localization of MMP-9 was determined by double labeling to microglia $(10 \mu \mathrm{l} / \mathrm{ml}$ FITC-labeled isolectin $\mathrm{B}_{4}$, L2895; Sigma-Aldrich), astrocytes (monoclonal anti-GFAP, 1:250, G3893; Sigma-Aldrich), and neurons (monoclonal anti-neuronal nuclei, 1:250, MAB377; Millipore). FITC-conjugated avi$\operatorname{din}(25 \mu \mathrm{l} / \mathrm{ml})$ or Texas Red-conjugated avidin $(25 \mu \mathrm{l} / \mathrm{ml})$ (Invitrogen) was used after incubation with biotinylated secondary antibody.

\section{$B B B$ permeability}

At $0,1,3,6,24$, and $72 \mathrm{~h}$ after the $\mathrm{HI}$ insult, pups ( $n=3$ per time point) were killed with an overdose of thiopental (pentothal sodium) intraperitoneally and perfusion fixed with 5\% paraformaldehyde, followed by $4 \mathrm{~h}$ postfixation and incubation in $20 \%$ sucrose in $0.1 \mathrm{~m}$ PBS solution. Freefloating sections $(80 \mu \mathrm{m})$ were incubated with biotinylated horse antimouse IgG (1:250 in PBS; Vector Laboratories). Immunoreactivity was visualized as described above. The immunohistochemical presence of laminin, a structural component of the BBB, was determined in the hippocampus $24 \mathrm{~h}$ after HI. The hippocampus in each hemisphere was outlined at low magnification $(1.5 \times)$ in each animal. Using stereological principles (Stereoinvestigator; MicroBrightField, Colchester, VT), 20 counting frames $(50 \times 50 \mu \mathrm{m})$ were randomly positioned within the hippocampus at equal distance from each other, and the number of laminin-positive profiles within each counting frame was determined at high magnification $(63 \times)$.

\section{Statistics}

Statistical analysis was performed using GraphPad Prism 4 software (GraphPad Software, San Diego, CA). The Mann-Whitney nonparametric ranking test or unpaired $t$ test was used for statistical comparisons between study groups. Values were considered significant at $p<0.05$, and data are presented as mean \pm SEM.

\section{Results \\ MMP activity after $\mathrm{HI}$}

The genotype of the animals was confirmed by PCR, with KO mice demonstrating a band at $480 \mathrm{bp}$ and WT mice demonstrating a band at 300 bp (Fig. 1A). No MMP-9 activity could be observed in MMP-9-deficient animals after HI, as confirmed by gelatin zymography (Fig. $1 \mathrm{~B}$ ). A weak expression of MMP-9 was seen $6 \mathrm{~h}$ after $\mathrm{HI}$ in the ipsilateral hemisphere in WT animals (Fig. $1 B$ ). At $24 \mathrm{~h}$ after HI, there was a marked increase in MMP-9 (Fig. $1 C$ ) and to a lesser extent at $72 \mathrm{~h}$ after HI (data not shown). Relatively low expression of the proenzyme of MMP-2 (72 kDa) was seen in the contralateral and ipsilateral hemispheres in both WT and MMP-9 KO animals at all time points after HI (Fig. $1 B, C)$.
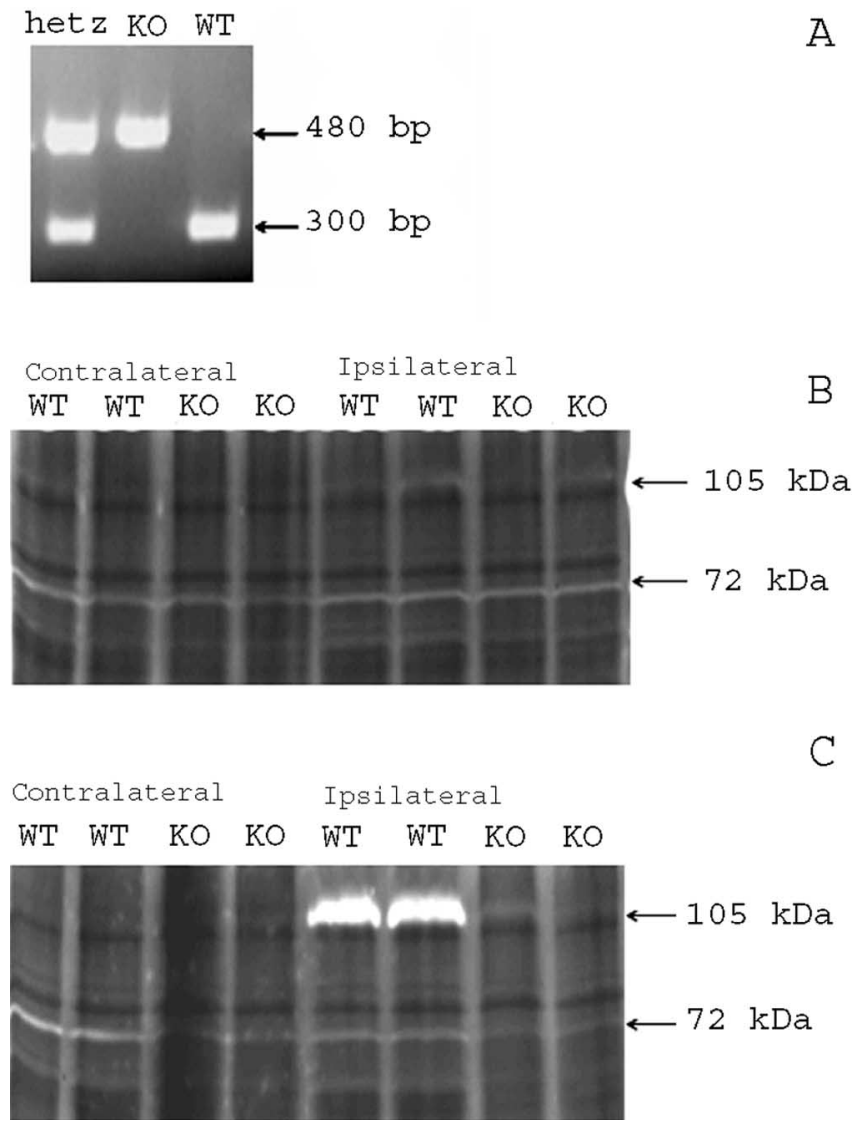

Figure 1. $\boldsymbol{A}$, The band of $480 \mathrm{bp}$ corresponds to the MMP-9 gene KO mice, and the band of 300 bp represents the MMP-9 gene in WT mice. Heterozygote (hetz) animals express both the 480 and 300 bp fragments. $\boldsymbol{B}, \boldsymbol{C}$, Gelatin zymograms show MMP-9 (105 kDa) weakly expressed at $6 \mathrm{~h}(\boldsymbol{B})$ and strongly at $24 \mathrm{~h}(\boldsymbol{C})$ after $\mathrm{Hl}$ in the ipsilateral hemisphere in WT animals. No MMP-9 activity was seen in the contralateral hemisphere or in MMP-9 K0 animals. MMP-2 activity (72 $\mathrm{kDa}$ ) was observed in all animals.

\section{MMP-9 immunoreactivity after $\mathrm{HI}$}

Very few MMP-9-positive cells, in either the ipsilateral or the contralateral hemisphere, could be detected in the brain at $0,1,3$, and $6 \mathrm{~h}$ after the insult. After $24 \mathrm{~h}$, an increase in cells expressing MMP-9 was observed in the hippocampus, thalamus, striatum, and cerebral cortex in the ipsilateral hemisphere (Fig. 2A). The highest density of MMP-9-positive cells was observed in the thalamus, with fewer cells in the cerebral cortex and hippocampus. By $72 \mathrm{~h}$ after HI, only a few positive MMP-9-positive cells were observed. No MMP-9-positive cells were found in the MMP-9 $\mathrm{KO}$ animals (Fig. 2B).

Double-labeling experiments showed that the MMP-9 expression was colocalized with microglia cells (isolectin-positive cells) (Fig. 2C-E) but not with neurons or astrocytes (Fig. $2 F-K$ ).

\section{Neuropathological outcome}

Brain injury evaluation

Brain injury was more severe in animals exposed to $60 \mathrm{~min} \mathrm{HI}$ (Fig. $3 A, B$ ) compared with $50 \mathrm{~min} \mathrm{HI}$ (Fig. 3C,D). Brain injury in the ipsilateral compared with the contralateral hemisphere at 14 evenly spaced brain levels was determined in MAP-2-stained sections. In animals that were exposed to $60 \mathrm{~min}$ of $\mathrm{HI}$, there was no significant difference in brain injury between MMP-9 KO $(n=$ $18)$ and WT $(n=19)$ mice at any of the brain levels examined (Fig. $3 A, B, E$ ), and there was no difference in the total volume of tissue loss between groups (WT, $38.6 \pm 2.0 \mathrm{~mm}^{3}$; KO, $38.4 \pm 2.0$ 
$\mathrm{mm}^{3} ; p=0.9636$ ) (Fig. 3G). In contrast, there was reduction in brain injury in MMP-9 KO animals at 13 of 14 brain levels (Fig. $3 F$ ) and in the total loss of tissue volume $\left(21.8 \pm 1.7 \mathrm{~mm}^{3} ; n=22\right)$ compared with WT animals $\left(32.3 \pm 2.1 \mathrm{~mm}^{3}\right.$; $n=22)$ after $50 \mathrm{~min}$ of $\mathrm{HI}(p=0.0006)$ (Fig. $3 G$ ).

\section{White-matter damage}

Injury to the subcortical white matter was examined 1 week after the HI insult by immunohistochemical analysis of the whitematter markers MBP and NF (Fig. 4A-D). A significant preservation of both NF and MBP was observed in the moderately injured group (NF: WT, $50.9 \pm 5.4 \%$; KO, $18.4 \pm 3.1 \% ; p<0.0001 ; \mathrm{MBP}: \mathrm{WT}$, $57.5 \pm 5.8 \% ; \mathrm{KO}, 23.2 \pm 3.5 \% ; p=$ 0.0001 ) (Fig. $4 E, F)$. In contrast, no differences were observed in the loss of whitematter markers in the severely damaged group (NF: WT, $74.6 \pm 4.8 \%$; KO, $69.8 \pm$ $5.4 \% ; p=0.5136$; MBP: WT, $72.9 \pm 4.2 \%$; $\mathrm{KO}, 68.2 \pm 4.5 \% ; p=0.4752$ ) (Fig. $4 E, F)$.

\section{BBB permeability}

BBB permeability was investigated immunohistochemically by the presence of IgG (Muramatsu et al., 1997) and laminin (Gu et al., 2005) in the brain. In animals exposed to severe $\mathrm{HI}$ (60 min), the BBB was open early at $3 \mathrm{~h}$ after $\mathrm{HI}$ and remained open at 6,24 , and $72 \mathrm{~h}$, with a maximum IgG immunoreactivity at $24 \mathrm{~h}$ after $\mathrm{HI}$ in both MMP-9 KO and WT animals (data not shown). In WT animals exposed to moderate HI (50 min), the IgG immunoreactivity pattern was similar to animals exposed to $60 \mathrm{~min}$ of $\mathrm{HI}$ with a BBB opening at 3, 6, 24, and $72 \mathrm{~h}$ (Fig. 5A,C). In contrast, MMP-9-deficient animals exposed to 50 min of HI demonstrated BBB opening only at 6 and $24 \mathrm{~h}$ after $\mathrm{HI}$ (Fig. 5B) and to a much lesser extent than the WT mice. Normal control animals showed no IgG immunoreactivity in the brain (data not shown). In WT animals exposed to $50 \mathrm{~min}$ hypoxia, there was a reduction in laminin in the ipsilateral hemisphere compared with the contralateral hemisphere (Fig. 5E, F,I), which was not seen in $\mathrm{KO}$ animals (Fig. 5G-I). There was no difference in laminin immunoreactivity in the contralateral hemisphere between WT and KO mice. The percentage of loss of laminin in the ipsilateral hemisphere was also greater in WT animals $(33.2 \pm 7.0 \%)$ compared with $\mathrm{KO}$ mice $(-0.9 \pm$ $8.1 \% ; p=0.0061)$.

Because neuropathological analysis of gray and white matter and $\mathrm{BBB}$ examination indicated that there were no differences between MMP-9 KO and WT animals after $60 \mathrm{~min} \mathrm{HI}$, only animals subjected to 50 min HI were analyzed further.

\section{Inflammation}

Microglial activation was evaluated in sections at the hippocampal level at $6 \mathrm{~h}, 24 \mathrm{~h}$, and $7 \mathrm{~d}$ after HI. Very few activated microglia cells were observed $6 \mathrm{~h}$ after HI (Fig. 6A), with a more robust inflammatory response at $24 \mathrm{~h}$ (Fig. $6 \mathrm{~B}$ ). There was no difference in any brain region investigated between MMP-9 KO and WT groups at either 6 or $24 \mathrm{~h}$ (Fig. 6A,B). In contrast, a significant attenuation in microglial activation was observed $7 \mathrm{~d}$ after $\mathrm{HI}$ in MMP-9 KO mice compared with WT animals (Fig. 6C).

\section{General cell death and apoptotic markers}

Cell death, as shown by DAPI staining, was reduced in $\mathrm{KO}$ animals at $24 \mathrm{~h}$ and $7 \mathrm{~d}$ after $\mathrm{HI}$ (Fig. 7A-E). The apoptotic markers AIF, cytochrome $c$, and caspase- 3 were investigated $6 \mathrm{~h}$ (AIF and cytochrome $c$ ) and $24 \mathrm{~h}$ (caspase-3) after HI ( $n=8$ animals/ group). Apart from a decrease in cytochrome $c$-positive cells in the CA1/2 area of the hippocampus in MMP-9 KO animals (Fig. $7 G)$, there were no alterations in apoptotic markers in the hippocampus or cortex (Fig. $7 F-H$ ). To also confirm neuroprotection in these animals, tissue loss was determined in MAP-2stained sections at $24 \mathrm{~h}$ after $\mathrm{HI}$, which showed a $26 \%$ reduction in injury in $\mathrm{KO}$ animals $(26.9 \pm 2 \% ; n=8)$ compared with WT $(36.3 \pm 4 \% ; n=8 ; p<0.05)$.

\section{Discussion}

This study shows that deletion of the MMP-9 gene reduces cerebral tissue volume loss, protects the white matter, and attenuates inflammation in the immature brain after a moderate HI insult. The neuroprotection is also associated with a delayed and reduced opening of the BBB. However, although general cell death is attenuated, neuroprotection after MMP-9 deficiency does not appear to be linked to either caspase-dependent or -independent apoptotic mechanisms. 


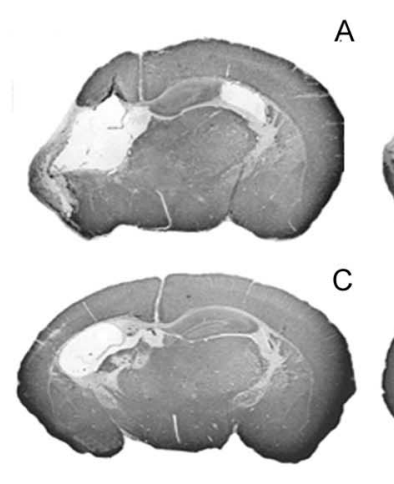

A

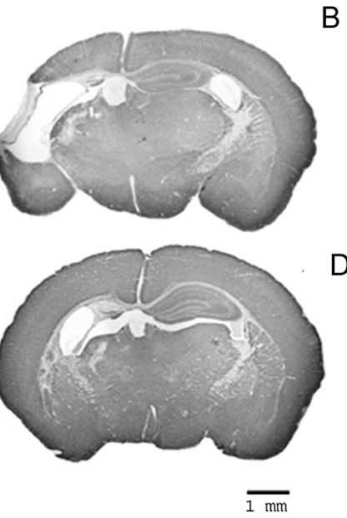

$E$
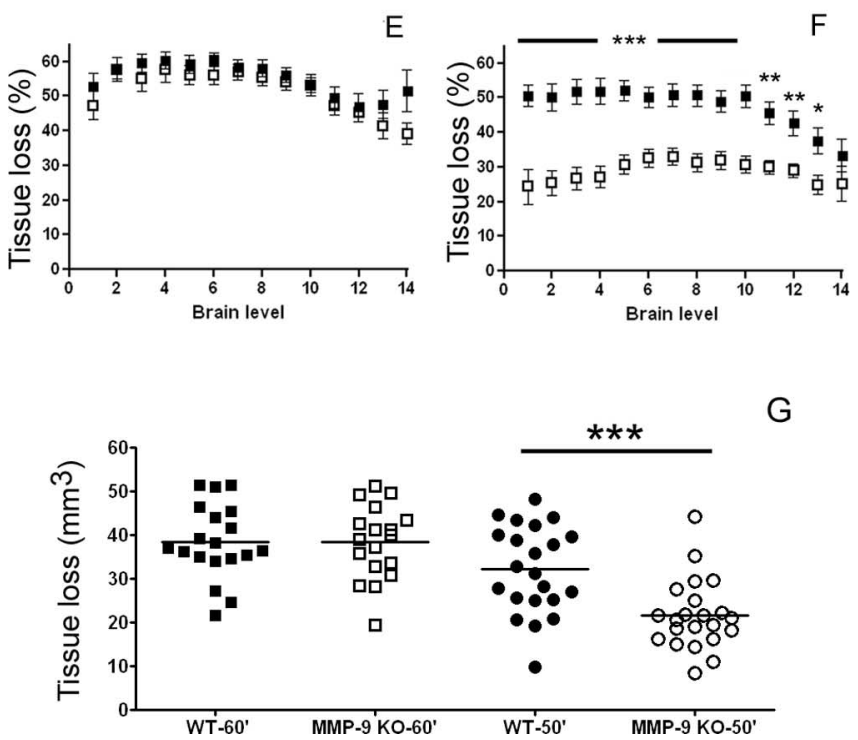

G

Figure 3. $A-D$, Immunohistochemical staining for MAP-2 in WT $(A, C)$ and MMP-9 KO $(B, D)$ animals $7 \mathrm{~d}$ after $\mathrm{HI}$. Animals exposed to $60 \mathrm{~min}$ of $\mathrm{HI}(\boldsymbol{A}, \boldsymbol{B})$ exhibit more severe brain injury compared with pups that were exposed to $50 \mathrm{~min}$ of $H I(C, D) . E, F$, Quantification of brain tissue loss based on MAP-2 staining at different brain levels after $\mathrm{HI}$ (posterior $\rightarrow$ anterior part of the brain). Tissue loss was reduced at 13 of 14 brain levels in MMP-9 K0 after $50 \mathrm{~min} \mathrm{HI}(\boldsymbol{F})$ but not after $60 \mathrm{~min} \mathrm{HI} \mathrm{(E).} \mathrm{G,} \mathrm{Total} \mathrm{brain} \mathrm{tissue} \mathrm{loss} \mathrm{(cubed} \mathrm{millimeters)} \mathrm{was} \mathrm{reduced} \mathrm{in} \mathrm{MMP-9} \mathrm{K0} \mathrm{after}$ $50 \mathrm{~min}$ HI but not $60 \mathrm{~min}$ H. Error bars indicate mean \pm SEM. ${ }^{*} p<0.05$; ${ }^{* *} p<0.01 ;{ }^{* * *} p<$ 0.001 compared with WT.

Neuroprotection after inhibition of MMP-9 activation has been demonstrated previously in the adult brain after focal cerebral ischemia in both the mouse and rat, either by using MMP9-deficient animals or MMP-9 inhibitors (Romanic et al., 1998; Asahi et al., 2000, 2001; Jiang et al., 2001). This is the first study to show activation of MMP-9 in immature animals after HI and neuroprotection in neonatal MMP-9-deficient mice. The neuroprotection was strongly dependent on the severity of the insult; pups exposed to severe HI (60 min) showed no difference in brain injury between WT and MMP-9 KO mice. In contrast, when pups were exposed to $50 \mathrm{~min} \mathrm{HI}$, there was marked reduction in brain injury in the MMP-9 KO animals compared with wild type. Similar severity of injury-dependent treatment effects after HI have also been noted in mice deficient in IL-1 converting enzyme (Liu et al., 1999)

In addition to the reduction in tissue loss, the injury to MBP and NFs was also attenuated in MMP-9-deficient animals, which is similar to studies of focal cerebral ischemia in adult MMP-9 gene $\mathrm{KO}$ mice that show reduced damage to white-matter components (Asahi et al., 2001).
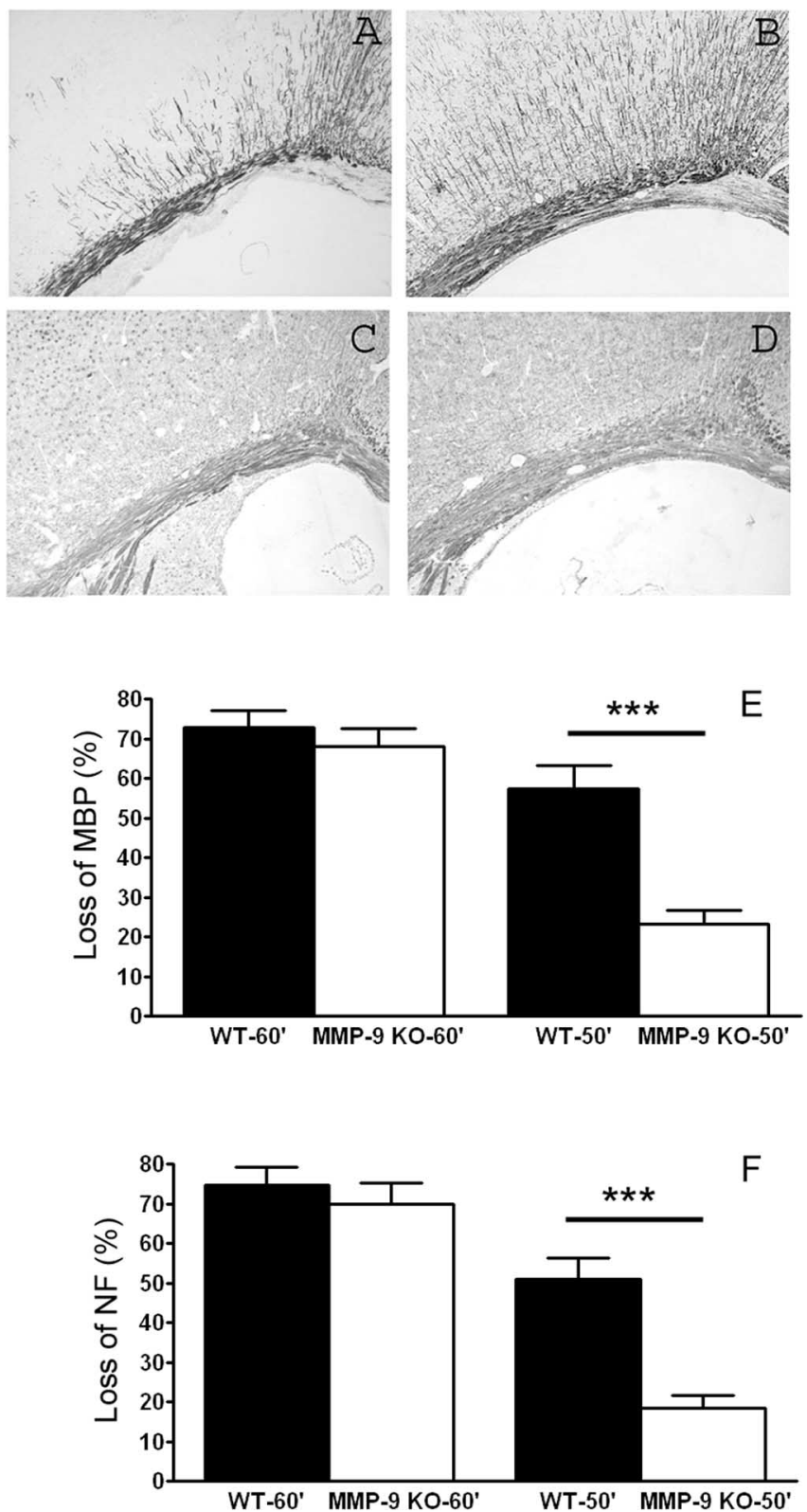

Figure 4. $\quad A-D$, White-matter injury was determined by the loss of $\operatorname{MBP}(A, B)$ and $\operatorname{NF}(C, D)$ in WT $(\boldsymbol{A}, \boldsymbol{C})$ and MMP-9 KO (B, D) animals $7 \mathrm{~d}$ after HI. $\boldsymbol{E}, \boldsymbol{F}$, After $50 \mathrm{~min}$ HI, MMP-9 KO animals demonstrated preservation of $M B P(\boldsymbol{E})$ and $\mathrm{NF}(\boldsymbol{F})$ compared with WT but not after $60 \mathrm{~min} \mathrm{HI}(\boldsymbol{E}$, $\boldsymbol{F})$. Immunohistochemical staining showed loss of MBP and NF in the ipsilateral hemisphere in WT animals compared with MMP-9 KO animals $(\boldsymbol{B}, \boldsymbol{D})$. Error bars indicate mean \pm SEM. ${ }^{* * *} p<$ 0.001 compared with WT.

It has been suggested that MMP-2 may play a role in the development of brain injury because the function of MMP-2 is similar to MMP-9; however, no effect has been reported on brain injury in adult MMP-2 KO mice after focal ischemia (Asahi et al., 2001). We observed the proform of MMP-2 in all animals after $\mathrm{HI}$, whereas the activated MMP-2 form was only observed in the ipsilateral hemisphere. However, there were no compensatory increases in MMP-2 in MMP-9 KO animals and no association of MMP-2 expression and brain injury, suggesting that MMP-2 activation is not deleterious in the immature brain.

The neuroprotection in MMP-9 KO animals after moderate HI was associated with a shorter period of BBB opening compared with either $50 \mathrm{~min} \mathrm{HI}$ in WT animals or $60 \mathrm{~min} \mathrm{HI} \mathrm{in} \mathrm{WT}$ 
A

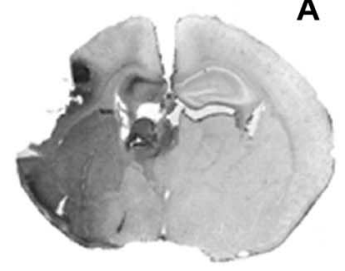

C
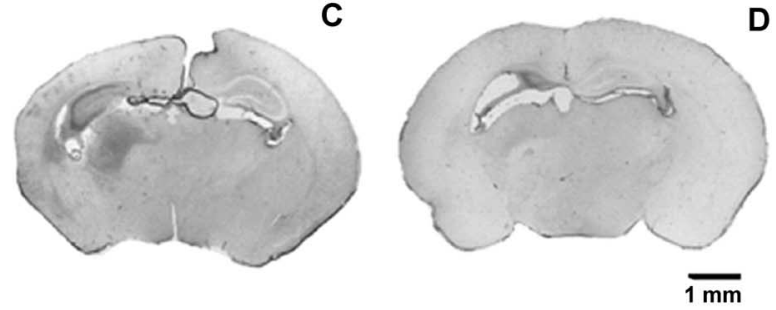

Ipsilateral
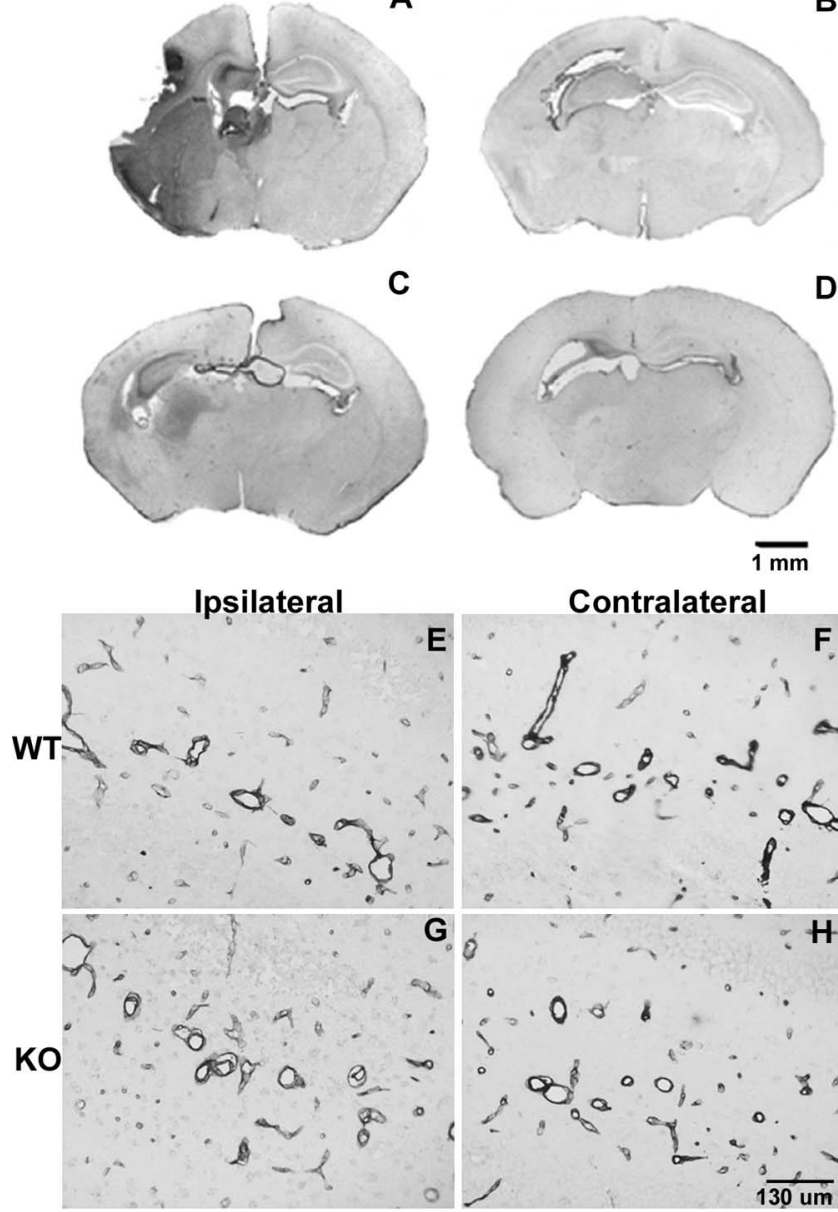

D

Contralateral
B

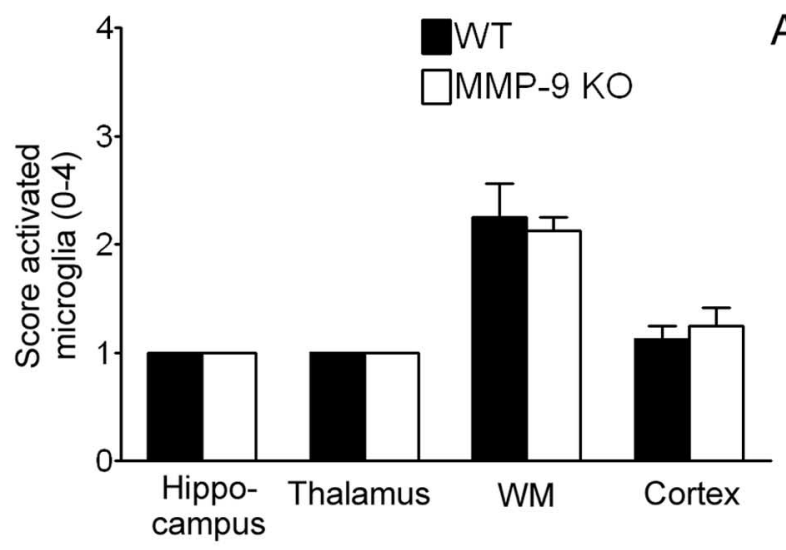

B
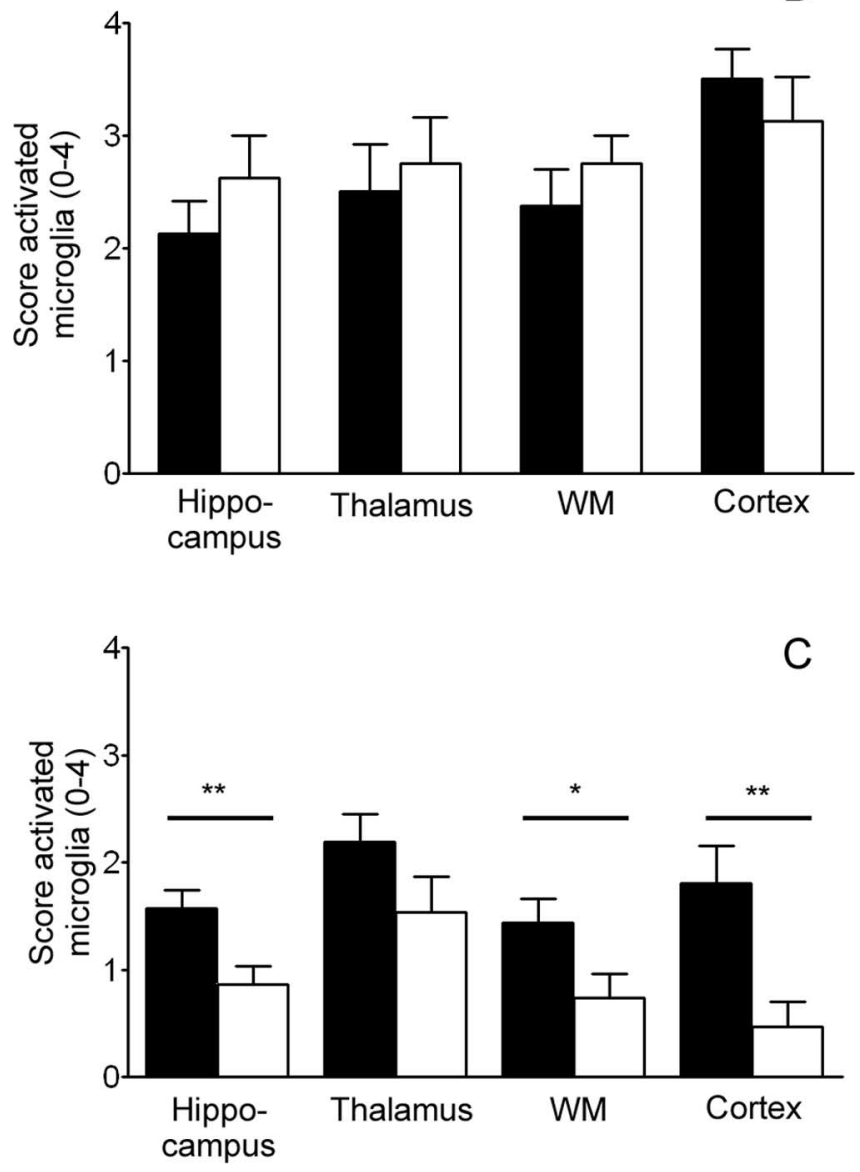

Figure 5. The integrity of the BBB was evaluated by histochemical analysis of $\mathrm{lg} G$ and laminin immunoreactivity at $24 \mathrm{~h}(\boldsymbol{A}, \boldsymbol{B}, \boldsymbol{E}-\boldsymbol{I})$ and $72 \mathrm{~h}(\boldsymbol{C}, \boldsymbol{D})$ after $\mathrm{HI}$ ( $n=3$ per group). $\boldsymbol{A}-\boldsymbol{D}, \mathrm{In}$ WT animals $(A, C)$, the BBB was disrupted at both 24 and $72 \mathrm{~h}$, whereas in the MMP-9-KO animals, the BBB opened only transiently at $24 \mathrm{~h}$ after $\mathrm{HI}(\boldsymbol{B})$ and was almost intact at $72 \mathrm{~h}$ after $\mathrm{HI}(\boldsymbol{D})$. $\boldsymbol{E}-\boldsymbol{I}$, Furthermore, there was a reduction in laminin-positive staining in the ipsilateral hemisphere $(\boldsymbol{E}, \boldsymbol{I})$ compared with the contralateral hemisphere $(\boldsymbol{F}, \boldsymbol{I})$ in WT animals, which was not seen in $\mathrm{K} 0$ animals $(\mathbf{G}-\mathbf{I}){ }^{* *} p<0.01$.

and MMP-9 KO mice. These results may suggest that the length of BBB opening after HI plays an important role in the brain injury. Particularly, the BBB opening in immature animals has been linked to the severity of injury (Muramatsu et al., 1997). MMP-9 has been shown to disrupt the BBB by degrading the basal lamina (collagen IV and laminin), and increased MMP activity at the BBB leads to MMP-dependent cleavage of tight junction proteins, such as zona occluden-1 and occludin, and a profound disruption of cell-cell contact (Harkness et al., 2000; Lohmann et al., 2004). Leakage of the BBB allows leukocytes and blood proteins to enter the brain. Interestingly, it was recently

Figure 6. Analysis of activated microglia at the hippocampal level at $6 \mathrm{~h}(\boldsymbol{A}), 24 \mathrm{~h}(\boldsymbol{B})$, and $7 \mathrm{~d}$ (C) after HI. In MMP-9 KO animals, there was increased microglia activation $7 \mathrm{~d}$ after $\mathrm{HI}$ in the hippocampus, white matter (WM), and cortex (C). Error bars indicate mean \pm SEM. ${ }^{*} p<0.05$; ${ }^{* *} p<0.01$.

suggested that the MMP-9 expression in peripheral leukocytes, rather than brain resident cells, was responsible for the $\mathrm{BBB}$ breakdown and subsequent brain injury after focal stroke in adult chimeric MMP-9 $9^{-1-}$ mice (Gidday et al., 2005).

According to the gelatin zymography results in the present study, MMP-9 activation in the ipsilateral hemisphere was observed $24 \mathrm{~h}$ after HI, which is similar to the time frame of MMP-9 activation previously observed in adult animals after ischemia (Wang et al., 2000; Asahi et al., 2001). In agreement with the zymography results, we found a transient increase in the number 

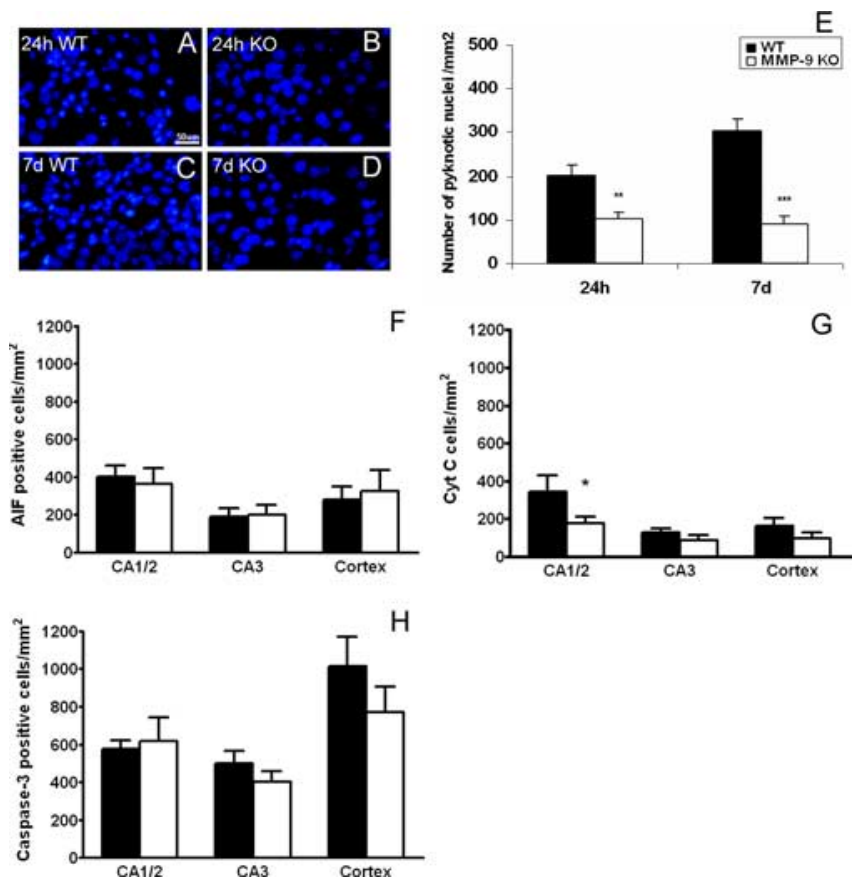

Figure 7. $\quad \boldsymbol{A}-\boldsymbol{D}$, Photomicrographs of DAPI staining at $24 \mathrm{~h}(\boldsymbol{A}, \boldsymbol{B})$ and $7 \mathrm{~d}(\boldsymbol{C}, \boldsymbol{D})$ after HI in WT $(\boldsymbol{A}, \boldsymbol{C})$ and $\mathrm{KO}(\boldsymbol{B}, \boldsymbol{D})$ animals. $\boldsymbol{E}$, There was a reduction in the number of DNA-damaged cells in $\mathrm{KO}$ animals at both $24 \mathrm{~h}$ and $7 \mathrm{~d}$ after $\mathrm{HI}(\boldsymbol{E})$. $\boldsymbol{F}-\boldsymbol{H}$, Cells positive for $\mathrm{AIF}(\boldsymbol{F})$ and cytochrome $c(\boldsymbol{G}) 6 \mathrm{~h}$ after $\mathrm{HI}$ and caspase-3 $\boldsymbol{( H )} 24 \mathrm{~h}$ after $\mathrm{HI}$ were determined immunohistochemically at the hippocampal level of the brain. Error bars indicate mean \pm SEM. ${ }^{*} p<0.05 ;{ }^{* *} p<0.01$; ${ }^{* * *} p<$ $0.001 ; n=8$ per group.

of MMP-9-immunoreactive cells in the ipsilateral hemisphere $24 \mathrm{~h}$ after $\mathrm{HI}$ but very little reactivity at later time points. This is in contrast with recent findings also demonstrating delayed MMP-9 activity in the peri-infarct cortex at $7 \mathrm{~d}$ and later after stroke in adult rats (Zhao et al., 2006).

MMP-9-immunopositive cells have been detected previously in neurons, glia cells, and blood vessels $48 \mathrm{~h}$ after transient middle cerebral artery occlusion in adult rats (Rosenberg et al., 2001). In adult human multiple sclerosis tissue, MMP-9 has also been found expressed in activated microglia, microvessel endothelial cells, and in small numbers of astrocytes (Cuzner et al., 1996; Maeda and Sobel, 1996). Also in in vitro studies, astrocytes (Apodaca et al., 1990; Gottschall and Deb, 1996), microglia (Colton et al., 1993; Gottschall and Deb, 1996), and oligodendrocytes (Uhm et al., 1998) were shown to express MMP-9 after different treatments. In contrast to the studies in adult tissue, the present study shows MMP-9 is colocalized with microglia after neonatal HI. Together, the MMP-9 expression data suggest that the timing of activation and localization of MMP-9 after brain injury may be age dependent.

The localization of MMP-9 in activated microglia cells suggests that inflammatory mechanisms may be involved in brain injury, which is in agreement with our previous study demonstrating a profound inflammatory response after $\mathrm{HI}$ in neonatal mice (Hedtjarn et al., 2004) and rats (McRae et al., 1995; Silverstein et al., 1997). Furthermore, the depletion of microgliainduced IL-18 confers neuroprotection to neonatal HI (Hedtjarn et al., 2002). MMP-9 has been shown to be able to process proforms of pro-inflammatory cytokines into active forms (Schonbeck et al., 1998), and cytokines are known to stimulate the production of MMP-9, which in turn disturbs the strict regulation of the protease and can lead to uncontrolled activation (Okada et al.,
1990; Lefebvre et al., 1991; Saren et al., 1996). The interaction between MMP-9 and inflammation may be of particular importance because previous studies have shown that injection of IL- $1 \beta$ into the brain resulted in an increased permeability of the BBB in juvenile animals but not in the adult (Anthony et al., 1997). In addition, when rats at different ages were exposed to HI, young animals had an increased opening of the BBB after the insult, whereas there was no opening in the adult animals (Muramatsu et al., 1997). Furthermore, there is an age-dependent difference in the vulnerability to several cytokines after cerebral ischemia (Hedtjarn et al., 2002, 2005; Wheeler et al., 2003). However, in the present study, the timing of the BBB opening did not appear to coincide with the increased activation of microglia in WT animals. This may be related to the findings by Gidday et al. (2005), suggesting that the peripheral inflammatory response is more important for BBB permeability than the local cerebral reactions.

In the adult, MMPs have been implicated in several cerebrovascular diseases, in which degradation of components of the extracellular matrix, including degradation of collagen type IV, have been identified as a deleterious response (Fatar et al., 2005). Furthermore, MMP-9 has been suggested to have direct effects on cell death via cleavage of neuronal laminin (Gu et al., 2005). However, MMP-9 has also been implicated in intracellular proteolytic cell death mechanisms, such as apoptosis (Mannello et al., 2005). We have shown previously that both caspasedependent and independent mechanisms are important in neonatal brain injury after HI (Zhu et al., 2005). In the present study, we also showed a clear induction of capase-3, cytochrome $c$, and AIF after HI. However, despite reduced injury, there was no difference in apoptotic markers between MMP-9-deficient and WT animals, suggesting that apoptotic injury processes play a minor role in MMP-9-related neuroprotection, which is similar to that observed after stroke in adult rats (Copin et al., 2005).

In conclusion, this study demonstrates that MMP-9 plays an important role in the development of hypoxic-ischemic injury in the immature brain. The neuroprotective effects of MMP-9 appear to be related to inflammatory processes rather than apoptosis.

\section{References}

Anthony DC, Bolton SJ, Fearn S, Perry VH (1997) Age-related effects of interleukin-1 beta on polymorphonuclear neutrophil-dependent increases in blood-brain barrier permeability in rats. Brain 120:435-444.

Apodaca G, Rutka JT, Bouhana K, Berens ME, Giblin JR, Rosenblum ML, McKerrow JH, Banda MJ (1990) Expression of metalloproteinases and metalloproteinase inhibitors by fetal astrocytes and glioma cells. Cancer Res 50:2322-2329.

Asahi M, Asahi K, Jung JC, del Zoppo GJ, Fini ME, Lo EH (2000) Role for matrix metalloproteinase 9 after focal cerebral ischemia: effects of gene knockout and enzyme inhibition with BB-94. J Cereb Blood Flow Metab 20:1681-1689.

Asahi M, Wang X, Mori T, Sumii T, Jung JC, Moskowitz MA, Fini ME, Lo EH (2001) Effects of matrix metalloproteinase-9 gene knock-out on the proteolysis of blood-brain barrier and white matter components after cerebral ischemia. J Neurosci 21:7724-7732.

Colton CA, Keri JE, Chen WT, Monsky WL (1993) Protease production by cultured microglia: substrate gel analysis and immobilized matrix degradation. J Neurosci Res 35:297-304.

Copin JC, Goodyear MC, Gidday JM, Shah AR, Gascon E, Dayer A, Morel DM, Gasche Y (2005) Role of matrix metalloproteinases in apoptosis after transient focal cerebral ischemia in rats and mice. Eur J Neurosci 22:1597-1608.

Cuzner ML, Gveric D, Strand C, Loughlin AJ, Paemen L, Opdenakker G, Newcombe J (1996) The expression of tissue-type plasminogen activator, matrix metalloproteases and endogenous inhibitors in the central nervous system in multiple sclerosis: comparison of stages in lesion evolution. J Neuropathol Exp Neurol 55:1194-1204. 
Fatar M, Stroick M, Griebe M, Hennerici M (2005) Matrix metalloproteinases in cerebrovascular diseases. Cerebrovasc Dis 20:141-151.

Gidday JM, Gasche YG, Copin JC, Shah AR, Perez RS, Shapiro SD, Chan PH, Park TS (2005) Leukocyte-derived matrix metalloproteinase-9 mediates blood-brain barrier breakdown and is proinflammatory after transient focal cerebral ischemia. Am J Physiol Heart Circ Physiol 289:H558-H568.

Gottschall PE, Deb S (1996) Regulation of matrix metalloproteinase expressions in astrocytes, microglia and neurons. Neuroimmunomodulation 3:69-75.

Gu Z, Cui J, Brown S, Fridman R, Mobashery S, Strongin AY, Lipton SA (2005) A highly specific inhibitor of matrix metalloproteinase-9 rescues laminin from proteolysis and neurons from apoptosis in transient focal cerebral ischemia. J Neurosci 25:6401-6408.

Harkness KA, Adamson P, Sussman JD, Davies-Jones GA, Greenwood J, Woodroofe MN (2000) Dexamethasone regulation of matrix metalloproteinase expression in CNS vascular endothelium. Brain 123:698-709.

Hedtjarn M, Leverin AL, Eriksson K, Blomgren K, Mallard C, Hagberg H (2002) Interleukin-18 involvement in hypoxic-ischemic brain injury. J Neurosci 22:5910-5919.

Hedtjarn M, Mallard C, Hagberg H (2004) Inflammatory gene profiling in the developing mouse brain after hypoxia-ischemia. J Cereb Blood Flow Metab 24:1333-1351.

Hedtjarn M, Mallard C, Iwakura Y, Hagberg H (2005) Combined deficiency of IL-1beta18, but not IL-1alphabeta, reduces susceptibility to hypoxiaischemia in the immature brain. Dev Neurosci 27:143-148.

Jiang X, Namura S, Nagata I (2001) Matrix metalloproteinase inhibitor KBR7785 attenuates brain damage resulting from permanent focal cerebral ischemia in mice. Neurosci Lett 305:41-44.

Lefebvre V, Peeters-Joris C, Vaes G (1991) Production of gelatin-degrading matrix metalloproteinases ("type IV collagenases") and inhibitors by articular chondrocytes during their dedifferentiation by serial subcultures and under stimulation by interleukin-1 and tumor necrosis factor alpha. Biochim Biophys Acta 1094:8-18.

Liu XH, Kwon D, Schielke GP, Yang GY, Silverstein FS, Barks JD (1999) Mice deficient in interleukin- 1 converting enzyme are resistant to neonatal hypoxic-ischemic brain damage. J Cereb Blood Flow Metab 19:1099-1108.

Lohmann C, Krischke M, Wegener J, Galla HJ (2004) Tyrosine phosphatase inhibition induces loss of blood-brain barrier integrity by matrix metalloproteinase-dependent and -independent pathways. Brain Res 995:184-196.

Maeda A, Sobel RA (1996) Matrix metalloproteinases in the normal human central nervous system, microglial nodules, and multiple sclerosis lesions. J Neuropathol Exp Neurol 55:300-309.

Mannello F, Luchetti F, Falcieri E, Papa S (2005) Multiple roles of matrix metalloproteinases during apoptosis. Apoptosis 10:19-24.

McRae A, Gilland E, Bona E, Hagberg H (1995) Microglia activation after neonatal hypoxic-ischemia. Brain Res Dev Brain Res 84:245-252.

Mun-Bryce S, Rosenberg GA (1998) Gelatinase B modulates selective opening of the blood-brain barrier during inflammation. Am J Physiol 274:R1203-R1211.

Muramatsu K, Fukuda A, Togari H, Wada Y, Nishino H (1997) Vulnerability to cerebral hypoxic-ischemic insult in neonatal but not in adult rats is in parallel with disruption of the blood-brain barrier. Stroke 28:22812288; discussion 2288-2289.

Okada Y, Tsuchiya H, Shimizu H, Tomita K, Nakanishi I, Sato H, Seiki M, Yamashita K, Hayakawa T (1990) Induction and stimulation of 92-kDa gelatinase/type IV collagenase production in osteosarcoma and fibrosarcoma cell lines by tumor necrosis factor alpha. Biochem Biophys Res Commun 171:610-617.
Rice III JE, Vannucci RC, Brierley JB (1981) The influence of immaturity on hypoxic-ischemic brain damage in the rat. Ann Neurol 9:131-141.

Romanic AM, White RF, Arleth AJ, Ohlstein EH, Barone FC (1998) Matrix metalloproteinase expression increases after cerebral focal ischemia in rats: inhibition of matrix metalloproteinase- 9 reduces infarct size. Stroke 29:1020-1030.

Rosenberg GA, Dencoff JE, McGuire PG, Liotta LA, Stetler-Stevenson WG (1994) Injury-induced 92-kilodalton gelatinase and urokinase expression in rat brain. Lab Invest 71:417-422.

Rosenberg GA, Cunningham LA, Wallace J, Alexander S, Estrada EY, Grossetete M, Razhagi A, Miller K, Gearing A (2001) Immunohistochemistry of matrix metalloproteinases in reperfusion injury to rat brain: activation of MMP-9 linked to stromelysin-1 and microglia in cell cultures. Brain Res 893:104-112.

Saren P, Welgus HG, Kovanen PT (1996) TNF-alpha and IL-1beta selectively induce expression of $92-\mathrm{kDa}$ gelatinase by human macrophages. J Immunol 157:4159-4165.

Schonbeck U, Mach F, Libby P (1998) Generation of biologically active IL-1 beta by matrix metalloproteinases: a novel caspase-1-independent pathway of IL-1 beta processing. J Immunol 161:3340-3346.

Sellebjerg F, Sorensen TL (2003) Chemokines and matrix metalloproteinase-9 in leukocyte recruitment to the central nervous system. Brain Res Bull 61:347-355.

Silverstein FS, Barks JD, Hagan P, Liu XH, Ivacko J, Szaflarski J (1997) Cytokines and perinatal brain injury. Neurochem Int 30:375-383.

Svedin P, Kjellmer I, Welin AK, Blad S, Mallard C (2005) Maturational effects of lipopolysaccharide on white-matter injury in fetal sheep. J Child Neurol 20:960-964.

Uhm JH, Dooley NP, Oh LY, Yong VW (1998) Oligodendrocytes utilize a matrix metalloproteinase, MMP-9, to extend processes along an astrocyte extracellular matrix. Glia 22:53-63.

Van den Steen PE, Dubois B, Nelissen I, Rudd PM, Dwek RA, Opdenakker G (2002) Biochemistry and molecular biology of gelatinase B or matrix metalloproteinase-9 (MMP-9). Crit Rev Biochem Mol Biol 37:375-536.

Vannucci SJ, Hagberg H (2004) Hypoxia-ischemia in the immature brain. J Exp Biol 207:3149-3154.

Vu TH, Shipley JM, Bergers G, Berger JE, Helms JA, Hanahan D, Shapiro SD, Senior RM, Werb Z (1998) MMP-9/gelatinase B is a key regulator of growth plate angiogenesis and apoptosis of hypertrophic chondrocytes. Cell 93:411-422.

Wang X, Jung J, Asahi M, Chwang W, Russo L, Moskowitz MA, Dixon CE, Fini ME, Lo EH (2000) Effects of matrix metalloproteinase-9 gene knock-out on morphological and motor outcomes after traumatic brain injury. J Neurosci 20:7037-7042.

Wheeler RD, Boutin H, Touzani O, Luheshi GN, Takeda K, Rothwell NJ (2003) No role for interleukin-18 in acute murine stroke-induced brain injury. J Cereb Blood Flow Metab 23:531-535.

Yong VW, Krekoski CA, Forsyth PA, Bell R, Edwards DR (1998) Matrix metalloproteinases and diseases of the CNS. Trends Neurosci 21:75-80.

Zhao BQ, Wang S, Kim HY, Storrie H, Rosen BR, Mooney DJ, Wang X, Lo EH (2006) Role of matrix metalloproteinases in delayed cortical responses after stroke. Nat Med 12:441-445.

Zhu C, Wang X, Hagberg H, Blomgren K (2000) Correlation between caspase- 3 activation and three different markers of DNA damage in neonatal cerebral hypoxia-ischemia. J Neurochem 75:819-829.

Zhu C, Wang X, Xu F, Bahr BA, Shibata M, Uchiyama Y, Hagberg H, Blomgren K (2005) The influence of age on apoptotic and other mechanisms of cell death after cerebral hypoxia-ischemia. Cell Death Differ 12:162-176. 